\title{
(72) ANALYSIS OF GROUND MOTIONS AT A LIQUEFIED SITE DURING THE 1995 GREAT HANSHIN EARTHQUAKE
}

\author{
M. A. Ansary, F. Yamazaki, T. Katayama and I. Towhata \\ University of Tokyo
}

\begin{abstract}
A nonlinear dynamic effective stress method which uses multi-spring stress-strain model was applied for the simulation of liquefaction phenomena at the Kobe Port Island site during the recent Great Hanshin earthquake. In this site, a vertical borehole array with a surface and three downhole accelerometers exist. The input motions were recorded directly at the base by the vertical array system. Computed and recorded ground motions and associated response spectra were found to be in good agreement. Coupled effects of two horizontal motions on the dynamic response and liquefaction of the ground were also examined.
\end{abstract}

\section{INTRODUCTION}

The recent Great Hanshin earthquake in the vicinity of Kobe liquefied many sites. Most of the liquefaction occurred under the level ground condition [1]. Many researchers [2,3] showed that liquefaction is more liable to occur under multi-directional loading than under uni-directional loading and total stress method like SHAKE would underestimate the response at longer periods [4]. So, in this study the authors used multi-spring model $[5,6]$ for effective stress dynamic response analysis of a liquefied site at the Kobe port area.

\section{LOCATION AND SITE CONDITION}

A one-dimensional vertical array is situated at the Kobe Port Island area, which is located $34.670^{\circ} \mathrm{N}$ and $135.208^{\circ}$ E. The location of the array is shown in Figure 1. The array consists of 4 three-component accelerometers at different depth of the borehole. Figure 2 shows soil condition at the site together with shear wave velocity (Vs), SPT N-value and position of the accelerometers. The water table is situated approximately at a depth of $4 \mathrm{~m}$ from the ground surface.

In this array site, orientation errors was detected from particle orbit plots of two horizontal components and were estimated by applying maximum correlation method[7]. The ground surface at this site was supposed to be liquefied, so accelerometer at GL-32 m was used as a reference point instead of accelerometer at GL $0 \mathrm{~m}$. The rotation angles are shown in Table 1. For further analysis for this study, corrected records were used.

\section{DESCRIPTION OF MULTI-SHEARING MODEL}

The effective stress model used in this study was proposed by Yamazaki et. al [5]. This model is composed of both deformation model with multiple non-linear springs and pore pressure model based on strain energy concept. Below a brief overview of the models are given.

The stress-strain model called the multi-spring model consists of two rigid rings and numerous nonlinear springs connected together. When it represents a soil element, external forces are applied to the inner ring while the outer ring is fixed. Relation between force and deformation of each spring follows RambergOsgood model with Masing rule as proposed by Ohsaki et al.[8]. For pore pressure model, it was assumed that excess pore water pressure is determined solely by accumulated shear strain energy and current values of shear stress of a soil element.

For lack of any experimental data for the site under study, the pore pressure parameters were determined using the experimental results of Toyura sand. Initial shear modulus for different soil layers were obtained

Table 1 Measured orientation errors for the downhole instruments with the instrument at GL-32m as reference point

\begin{tabular}{lccc}
\hline $\begin{array}{l}\text { Seismometer } \\
\text { locations }\end{array}$ & $\begin{array}{c}\alpha \\
\text { (deg.) }\end{array}$ & $\begin{array}{c}\beta \\
\text { deg.) }\end{array}$ & $\begin{array}{c}\gamma \\
\text { (deg.) }\end{array}$ \\
\hline GL 0m & 0.0 & 0.0 & 0.0 \\
GL-16m & 0.0 & 0.0 & 0.0 \\
GL-83m & 19.0 & 0.0 & 0.0 \\
\hline
\end{tabular}

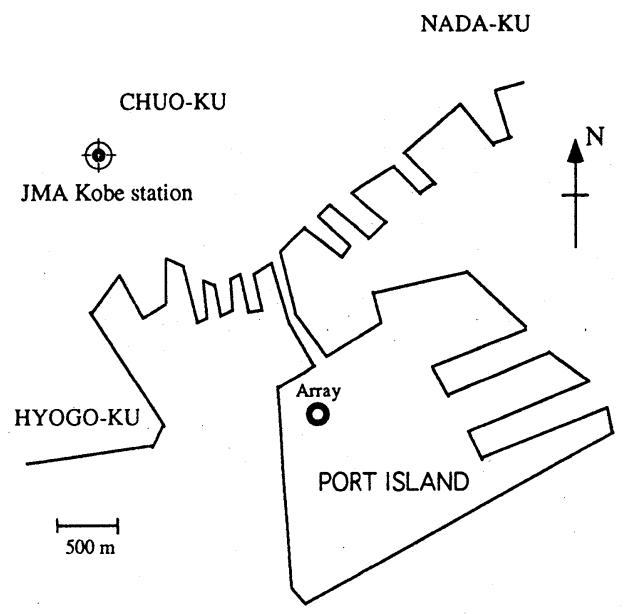

Fig. 1 Location of Port Island array and JMA station in Kobe 
from PS-logging and $\phi$ 'values from SPT N- $\phi$ 'relation. It was assumed that for clay layers there would be no pore pressure rise. For sand and gravel layers pore pressure parameters $a$ and $r$ were determined by using the relations between shear strain energy $\left(W_{s}\right)$ and pore water pressure at zero shear stress $\left(u_{o}\right)$ for different relative densities suggested by Towhata [9]. The values of $W_{s}$ and $u_{o}$ obtained for a particular relative density were normalized by initial effective stress $\left(\sigma_{z o}^{\prime}\right)$ and put in the empirical relations suggested by Yamazaki et al. [5] to obtain parameters $a$ and $r$. The empirical relations are shown below.

$$
\begin{aligned}
& \frac{u_{o}}{\sigma_{z o}^{\prime}}=\frac{1}{1+\left(\frac{r}{\left(W_{s} / \sigma_{z o}^{\prime}\right)}\right)^{a}} ; \text { if } \mathrm{u}_{\mathrm{O}} / \sigma_{\mathrm{zO}}^{\prime} \leq 0.5 \\
& \frac{u_{o}}{\sigma_{z o}^{\prime}}=\frac{a}{4}\left(\ln \left(W_{s} / \sigma_{z o}^{\prime}\right)-\ln r\right)+0.5 ; \text { if } 0.5<\mathrm{u}_{\mathrm{O}} / \sigma_{\mathrm{zO}}^{\prime} \leq 1.0
\end{aligned}
$$

The relative density, $D_{r}$ for different sands were obtained using Gibbs-Holtz(1957) [10] empirical relation shown as below,

$$
D_{\mathrm{r}}=21 \sqrt{\frac{\mathrm{N}}{\sigma_{\mathrm{v}}+0.7}}
$$

where, $\sigma_{\mathrm{v}}{ }^{\prime}$ is effective overburden pressure in $\mathrm{kgf} / \mathrm{cm}^{2}$. The soil

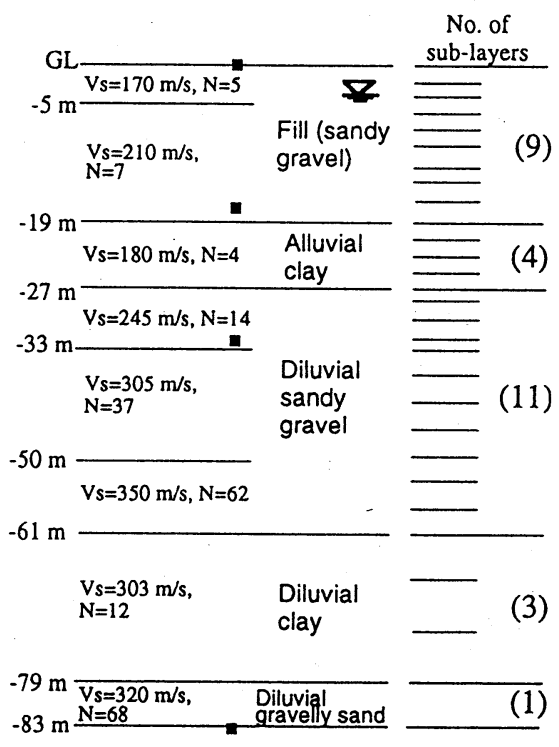

Fig. 2 Soil condition at the site (left), layering used for the analysis (right) and accelerometer locations (Dark squares) parameters used for this study were shown in Table 2.

In order to carry out the integration with respect to the depth, the horizontal soil layers were divided into a number of layers. These layers were converted into a lump-mass system as shown in Figure 3 in which the masses are connected by the multi-spring model.

\section{ANALYSIS OF THE SITE}

The method of dynamic response analysis using effective stress method and multi-directional shearing for soil element was first applied for Kawagishi-cho site during the 1964 earthquake in Niigata. The detailed description of the analysis procedure was given by Yamazaki et. al. [5] and case studies of liquefaction in the earthquake was reported by Ishihara and Koga [11]. For the analysis of that site the input used in the base layer were rescaled records of the earthquake observed in the basement of a nearby building. Also the site contained almost uniform soil condition, i.e., medium to fine sand. On the other hand, the site under consideration has some deep clay layers interspersed with sandy gravel layers which might be the cause for generation of liquefaction in deep layers. So, this site may be a good opportunity to check the effectiveness of the proposed model for liquefaction analysis.

The acceleration records obtained in the GL-83 $\mathrm{m}$ in the vertical array was directly used as the incident waves. The maximum amplitudes are $560.54 \mathrm{gal}$ in NS-direction and $456.98 \mathrm{gal}$ in EW-direction. The dynamic effective stress analyses in two-directional motion and in uni-directional motion were conducted. Results of those analyses are shown in Figures 4 to 8.

In general, the agreement between computed and observed results is fairly well, where as a little discrepancy in peak heights and shift of peak locations appear in some part of the time histories. This may be due to the fact that, the residual stiffness and strength assumed for the post-liquefied soil are too soft. The other factors that contribute to the discrepancy between recorded and computed motions may arise from the nature of the ground motions and the assumptions used in the 1D-analysis.

Figure 4 shows distribution of the computed maximum accelerations for NS-component together with the recorded values. It can be seen that except for some top soil layers in most of the layers, maximum acceleration by two-directional analysis are smaller than the uni-directional analysis.

Liquefaction may occur in more than one layer and at different times. In case of two-directional analysis, liquefaction occurred in the loose layer at GL-10m to $-16 \mathrm{~m}$ (i.e., layer \#6 to \#8) and also at GL-27m to $-33 \mathrm{~m}$ (layer \#14 to \#17). The liquefaction occurred first in the lower level and later. in the upper level. The liquefaction in the lower level which occurred first can be explained by Finn et al's parametric study [12]. According to that study, if a saturated sand stratum is sealed on both sides by impermeable surfaces there will be no external drainage but an internal redistribution of pore-water pressure will take place. This will 
Table 2. Soil-properties used for the analysis of Port-island array

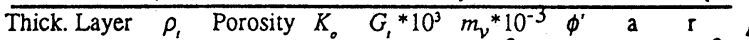
(m) Div. $\left(\mathrm{g} / \mathrm{cm}^{3}\right) \quad n \quad$ value $\left(\mathrm{kN} / \mathrm{m}^{3}\right) \quad\left(\mathrm{m}^{2} / \mathrm{t}\right) \quad($ deg. $) \quad \cdot 10^{-3}$

\begin{tabular}{llllllllll}
\hline 2.0 & 1 & 1.85 & 0.60 & 0.5 & 53.46 & - & 33.0 & - & - \\
2.0 & 2 & 1.85 & 0.60 & 0.5 & 53.46 & - & 33.0 & - & - \\
2.0 & 3 & 1.85 & 0.60 & 0.5 & 81.59 & 1.80 & 34.0 & 0.818 & 2.03 \\
2.0 & 4 & 1.85 & 0.60 & 0.5 & 81.59 & 1.80 & 34.0 & 0.818 & 2.03 \\
2.0 & 5 & 1.85 & 0.60 & 0.5 & 81.59 & 1.80 & 34.0 & 0.818 & 2.03 \\
2.6 & 6 & 1.85 & 0.60 & 0.5 & 81.59 & 1.80 & 34.0 & 0.818 & 2.03 \\
1.4 & 7 & 1.95 & 0.60 & 0.5 & 86.00 & 1.80 & 34.0 & 0.818 & 2.03 \\
2.0 & 8 & 1.95 & 0.60 & 0.5 & 86.00 & 1.80 & 34.0 & 0.818 & 2.03 \\
3.0 & 9 & 1.95 & 0.60 & 0.5 & 86.00 & 1.80 & 34.0 & 0.818 & 2.03
\end{tabular}

$\begin{array}{llllllllll}3.0 & 9 & 1.95 & 0.60 & 0.5 & 86.00 & 1.80 & 34.0 & 0.818 & 2.03\end{array}$

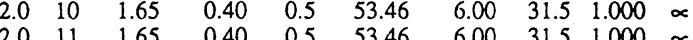

$\begin{array}{llllllllll}2.0 & 11 & 1.65 & 0.40 & 0.5 & 53.46 & 6.00 & 31.5 & 1.000 & \propto \\ 2.0 & 12 & 1.65 & 0.40 & 0.5 & 53.46 & 6.00 & 31.5 & 1.000 & \propto\end{array}$

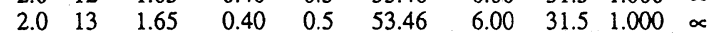

$\begin{array}{llllllllll}1.0 & 14 & 1.95 & 0.35 & 0.6 & 117.05 & 0.90 & 38.0 & 0.818 & 2.03\end{array}$

$\begin{array}{llllllllll}2.0 & 15 & 1.95 & 0.35 & 0.6 & 117.05 & 0.90 & 38.0 & 0.818 & 2.03\end{array}$

$\begin{array}{llllllllll}2.0 & 16 & 1.95 & 0.35 & 0.6 & 117.05 & 0.90 & 38.0 & 0.818 & 2.03\end{array}$

$\begin{array}{llllllllll}1.0 & 17 & 1.95 & 0.35 & 0.6 & 117.05 & 0.90 & 38.0 & 0.818 & 2.03\end{array}$

$\begin{array}{llllllllll}4.0 & 18 & 1.95 & 0.35 & 0.6 & 181.40 & 0.90 & 46.0 & 0.715 & 2.73\end{array}$

$\begin{array}{llllllllll}4.0 & 19 & 1.95 & 0.35 & 0.6 & 181.40 & 0.90 & 46.0 & 0.715 & 2.73\end{array}$

$\begin{array}{llllllllll}4.0 & 20 & 1.95 & 0.35 & 0.6 & 181.40 & 0.90 & 46.0 & 1.000 & \propto\end{array}$

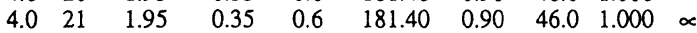

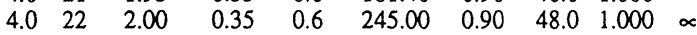

$\begin{array}{llllllllll}4.0 & 23 & 2.00 & 0.35 & 0.6 & 245.00 & 0.90 & 48.0 & 1.000 & \propto\end{array}$

$\begin{array}{llllllllll}4.0 & 24 & 2.00 & 0.35 & 0.6 & 245.00 & 0.90 & 48.0 & 1.000 & \propto\end{array}$

$\begin{array}{llllllllll}6.0 & 25 & 1.95 & 0.30 & 0.7 & 179.30 & 0.75 & 46.0 & 1.000 & \propto\end{array}$

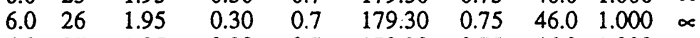

$\begin{array}{llllllllll}6.0 & 27 & 1.95 & 0.30 & 0.7 & 179.30 & 0.75 & 46.0 & 1.000 & \propto\end{array}$

$\begin{array}{llllllllll}4.0 & 28 & 2.00 & 0.30 & 0.7 & 204.80 & 0.90 & 52.0 & 1.000 & \propto\end{array}$

Soil constants below are adopted for all layers: permeability $=10^{-8}$ (clay), $10^{-3}$ (sand) and $10^{-2}$ (gravel) all in $\mathrm{m} / \mathrm{s}$, failure strain $=0.03$, maximum damping ratio $=0.35$, correction factor for multi-spring $=0.80, c_{p}=0.05$

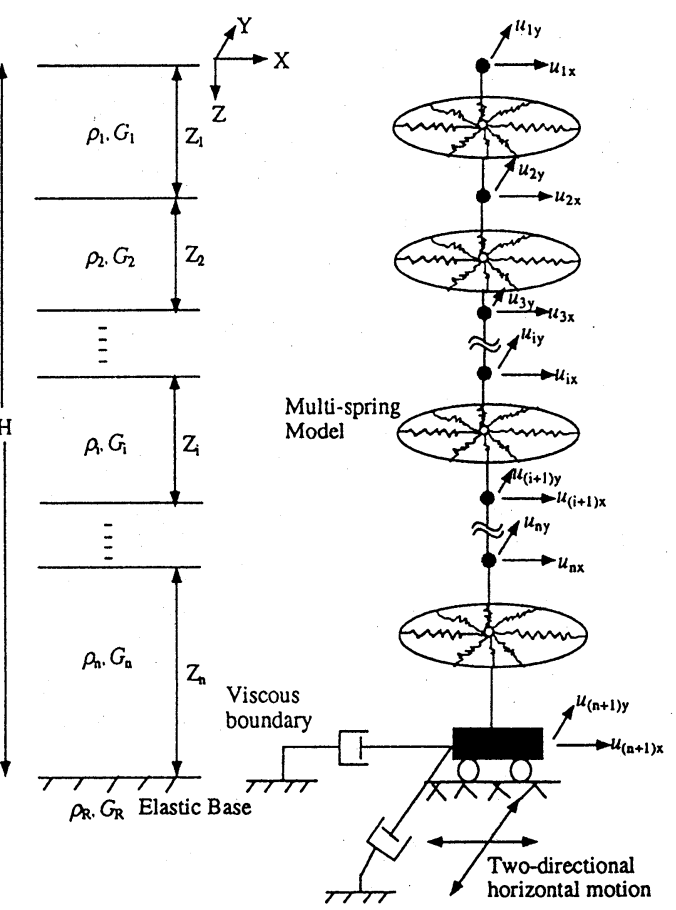

Fig. 3 Model for dynamic response analysis in twodirectional horizontal motion

ultimately raise the the level of initial liquefaction and decrease the time to liquefaction within the sand layer. On the other hand, liquefaction in the upper layers which occur later can be explained by the fact that liquefaction may also occur after an earthquake ceases due to the seepage forces exerted by the upward flow of water as the pore-water pressures remaining in the soil will try to dissipate in the vertical direction. Generally, this type of liquefaction occurs near the ground surface.

In the case of uni-directional analyses the maximum pore water pressures developed in the layer \#6 were $98 \%$ of the initial effective vertical stress by both NS and EW-motions. For layer \#14, maximum pore water pressures developed were $93 \%$ and $98 \%$ of the initial effective vertical stress by NS and EW-motions, respectively.

Figures 5 and 6 show maximum shear strain and maximum pore-water pressure variation with depth. From

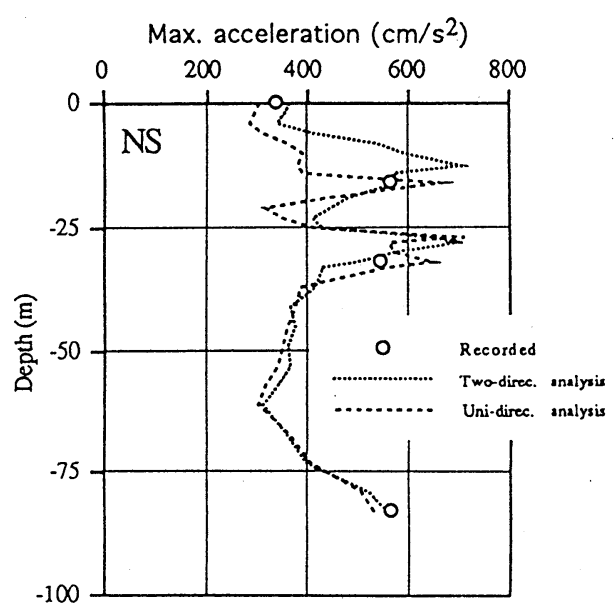

Fig.4 Distribution of the computed maximum accelerations for NS component
Max. shear strain

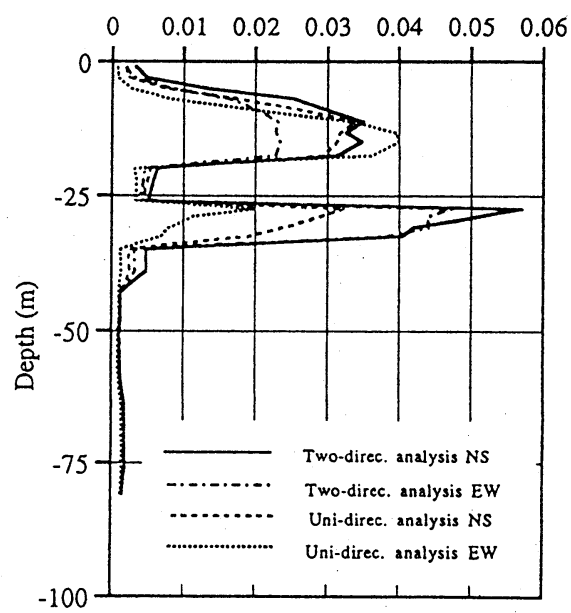

Fig.5 Distribution of the computed maximum shear strain 
these figures, it can be clearly seen that at the liquified layers pore-water pressure equals the initial effective vertical stress of the layer and shear strain exceeds the failure strain of the layer. From Figure 7, computed time history of pore-water pressure in a liquefied layer can be seen. In this figure, for GL-10 m (10-30 s), complete liquefaction was observed at 29.42 s. Figure 8 shows particle traces of shear stress and shear strain in the horizontal plane of a liquified layer.

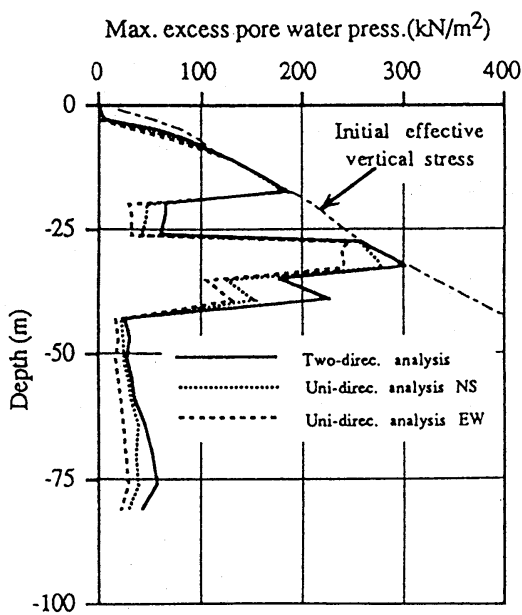

Fig. 6 Distribution of the computed maximum pore-water pressure

\section{CONCLUSION}

From this study following conclusion can be drawn:

There seems to be a relative orientation error in the vertical array. Using only the one earthquake event at hand the authors detected a major orientation error in the deepest point of the array. Further analysis should be made with several earthquake events to establish this point.

The proposed model can well simulate the liquefaction phenomena at the site. The results of this analysis showed that the combined two-directional input motion is more liable to cause liquefaction but induces smaller acceleration response spectrum than uni-directional input motion. The reason may be attributed to the intensification of the non-linearities by the combined motion.

For this particular site, along with the liquefaction at a shallow depth, liquefaction was also detected in a deep layer. The reason may be the presence of two clay layers, one at the top and the other at the bottom of the liquefied layer.

\section{REFERENCES}

1. K. Ishihara,'Liqefaction and flow failure during earthquakes', Geotechnique, 43(3), 351-415 (1993).

2. H. B. Seed, R. M. Pyke and G. R. Martin,'Effect of multi-directional shaking on pore pressure development in sands', Proc. ASCE, GT1, 104, 27-44 (1978).

3. Y. Yamada and K. Ishihara,'Undrained deformation characteristics of sand in multi-directional shear', Soils and Foundations, JSSMFE, 20(1), 61-79 (1983).

4.W. D. Liam Finn, C. E. Ventura and G. Wu,'Analysis of ground motions at Treasure island site during the 1989 Loma Prieta earthquake', Soil Dynamics and Earthquake eng., 12, 383-390 (1993).

5. F. Yamazaki, I. Towhata and K.Ishihara,'Numerical model for liquefaction problem under multi-directional shearing on horizontal plane', Fifth Int. conf. on Numerical Methods in Geomechanics, Nagoya, 399-406 (1985).

6. I. Towhata and K.Ishihara,'Modelling soil behavior under principal stress axes rotation', Fifth Int. conf. on Numerical Methods in Geomechanics, Nagoya, 523530 (1985).

7.F. Yamazaki, L. Lu, and T. Katayama'Orientation error estimation of buried seismographs in array obserevation', Earthquake eng. struct. dyn., 21, 679-694 (1992).

8. Y. Ohsaki, A. Hara and Y. Kiyota,'Stress-strain model of soils for seismic analysis', Proc. of Sth Japan earthquake eng. symp., 697-703 (1978).

9. I. Towhata and K. Ishihara,'Shear work and pore water pressure in undrained shear', Soils and Foundations, JSSMFE, 25(3) $73-84$ (1985).

10. H. J. Gibbs ad W. G. Holtz,'Research on determining the density of sands by spoon penetration testing', Fourth ICSMFE, 1, 35-39 (1957).

11. K.Ishihara and Y. Koga.'Case studies of liquefaction in the 1964 Niigata earthquake', Soils and Foundations, JSSMFE, 21(3) 35-52 (1981).

12. W. D. Liam Finn, K. W Lee and G. R. Martin,' An effective stress model for liquefaction', J. Geotech. Engg. Div., ASCE, 103(GT6), 517-533 (1977). 